\title{
Out-of-Cloud Convective Turbulence: Estimation Method and Impacts of Model Resolution
}

\author{
KATELyn A. BARber AND GRETCHEN L. Mullendore \\ University of North Dakota, Grand Forks, North Dakota \\ M. JOAN ALEXANDER \\ Northwest Research Association, Boulder, Colorado
}

(Manuscript received 21 June 2017, in final form 15 October 2017)

\begin{abstract}
Convectively induced turbulence (CIT) poses both a serious threat to aviation operations and a challenge to forecasting applications. CIT generation and propagation processes occur on scales between 10 and $1000 \mathrm{~m}$ and therefore are best treated with high-resolution cloud-resolving models. However, high-resolution model simulations are computationally expensive, limiting their operational use. In this study, summertime convection in the North Dakota region is simulated over a 1-week period using a variety of model setups that are similar to those utilized in operational and research applications. Eddy dissipation rate and Ellrod index, both popular turbulence metrics, are evaluated across various model resolutions and compared with pilot reports from aircraft. The Ellrod index was found to be extremely sensitive to model resolution and overestimated turbulence intensity. The variability of turbulence values with respect to model resolution and distance away from convection is also examined. Turbulence probability was found to be the greatest when farther than $20 \mathrm{mi}(32.2 \mathrm{~km})$ away from convective cores. Model resolution was found to influence the intensity of predicted turbulence, and the model setup with the highest horizontal and vertical resolution predicted the highest turbulence values. However, the influence on turbulence intensity of vertical resolution and convective properties, such as storm depth, was found to be minimal for 3-km horizontal grid spacing.
\end{abstract}

\section{Introduction}

Convectively induced turbulence (CIT) is an aviation hazard that can cause moderate to severe damage to aircraft and costs the aviation industry millions of dollars (Golding 2000). CIT often occurs in the immediate area around convection because of moist instabilities and mixing (Lane et al. 2003), particularly near updrafts, downdrafts, and anvil cloud features. However, CIT is not limited to the immediate cloud area and can occur more than $100 \mathrm{~km}(62 \mathrm{mi})$ away from convective areas (Lane and Sharman 2014; Lane et al. 2012; Pantley 1989; U.S. Department of the Air Force 1982). The three mechanisms known to generate out-of-cloud CIT are 1) enhancement of the background wind shear by convection penetrating into the upper troposphere, 2) cloud-induced deformation at the cloud boundary caused by buoyancy gradients, and

\footnotetext{
Corresponding author: Katelyn A. Barber, katelyn.barber@und. edu
}

3) convectively generated gravity waves that propagate and break above convection (Lane et al. 2003). The operational prediction of CIT is challenging because it occurs on very small scales and can occur outside of cloud boundaries in regions where onboard radar does not indicate turbulent conditions (e.g., Kim and Chun 2012). To reduce the number of convection related incidents (including CIT), the Federal Aviation Administration (FAA) has guidelines in place that recommend pilots remain $20 \mathrm{mi}(32.2 \mathrm{~km})$ away from severe convection (Federal Aviation Administration 2017).

Traditionally, forecast models have had limited success with turbulence prediction because the utilized model resolution is too coarse to resolve individual turbulent eddies. To mitigate this problem, several metrics have been developed to diagnose turbulence on larger synoptic scales. These indices include the Brown index, the Dutton index, the Ellrod index, and the Ellrod-Knox index (Brown 1973; Dutton 1980; Ellrod and Knapp 1992; Ellrod and Knox 2010). A major limitation with all of these indices for CIT prediction is that 
the turbulence intensity is an empirical value determined from correlating large-scale meteorological variables to pilot reports that did not include CIT. In addition, the turbulence thresholds were determined based on model simulations with much coarser model resolutions than are in operation today. Behne (2008) reported an overestimation of turbulence potential when implementing the Ellrod index. This overestimation by the Ellrod index was also noted in a recent study of tropical cases (Barber 2015). Although a conservative estimation of turbulence may seem to be a safe way of approaching air travel, in reality the estimate influences flight routes, traffic patterns, takeoffs, and landings, and is overall economically inefficient. Therefore, more accurate turbulence prediction that maintains safety and is economically efficient is needed.

More recently, high-resolution numerical models are being used to gain a better understanding of the generation, propagation, and dissipation of out-of-cloud turbulence (e.g., Lane et al. 2009; Trier et al. 2010; Sharman et al. 2012; Lane et al. 2012; Kim et al. 2014; Lane and Sharman 2014; Trier and Sharman 2016). However, simulating CIT using high-resolution models is challenging because the scale of motion that influences aircraft (10-1000 m; Lester 1994) is similar to or smaller than the scale of mesoscale processes (Bryan et al. 2003) that generate CIT. Accurately resolving both the mesoscale source and turbulent response simultaneously is critical for turbulence prediction (Lane and Sharman 2014; Zovko-Rajak and Lane 2014). Previous simulations of gravity waves with varied resolution found that finer-resolution simulations resulted in an increase in the total power of gravity waves and the vertical propagation of gravity waves (Lane and Knievel 2005), both of which would influence turbulence prediction. Doyle et al. (2011) found that when using a variety of numerical models for mountain wave prediction, gravity wave characteristics were dramatically different between the setups. Lane and Sharman (2014), using large-eddy simulations, found that the most intense turbulence locations were outside of the convective cloud, well beyond the FAA guidelines, and not within cloud. An additional challenge specific to forecasting CIT is correctly forecasting the location, strength, and type of convection (McNulty 1995; Bernardet et al. 2000; Weisman et al. 2008; Wakimoto and Murphey 2009). Last, the computational and temporal expenses limit the use of high-resolution models in an operational forecast environment for turbulence prediction.

CIT prediction depends on model resolution and the accuracy of convective forecasts. The goal of this research is to identify statistical biases in popular turbulence metrics estimated from both common operational model setups and high-resolution simulations. Biases in convection will also be investigated amongst various model setups and convective morphologies. Turbulence is estimated from Weather Research and Forecasting (WRF) Model simulations over a 1-week period over the North Dakota region in July 2015. The results are compared with observed pilot reports collected from various airlines. Out-of-cloud turbulence estimations are included in the analysis of model accuracy. The biases found will be useful for ongoing development of resolution-dependent turbulence intensities for independent indices.

\section{Data and methods}

\section{a. Pilot reports}

Pilot reports (PIREPs) gathered from the Aviation Weather Center (A. Terborg 2016, personal communication) and the Iowa Environmental Mesonet (https://mesonet.agron.iastate.edu/request/gis/pireps. $\mathrm{php}$ ) are used as observations of turbulence from various aircraft in the northern Great Plains region during 10-17 July 2015. These reports include the estimated turbulence intensity, time, and location of the turbulence encounter, and whether the aircraft was in cloud or out of cloud at the time. PIREPs that are reported on a $0-8$ scale can be converted to eddy dissipation rate (EDR) values following the methodology outlined in Sharman and Pearson (2017) and Sharman et al. (2014). A caveat with this conversion is that the constants may be height dependent. While PIREPs are extremely helpful for nowcasting turbulence and aiding in turbulence avoidance, there are numerous limitations associated with the use of PIREPs in scientific research. PIREPs give a limited validity of turbulence location and intensity for scientific research and are dependent on pilot perception of turbulence, especially when in situ measurements of EDR are unavailable. In addition, turbulence at various scales impacts aircraft of various sizes differently. Specifically, moderate turbulence encountered by a small general public aircraft may not be moderate turbulence to a larger commercial aircraft. Another critical limitation of PIREPs is that most aviation routes are going to avoid convection based on company-determined lateral and vertical distances. This avoidance drastically decreases the number of CIT observations and restricts direct comparisons with model output. Last, PIREPs without in situ EDR measurements are subject to human error and can be reported incorrectly (Sharman et al. 2014; Wolff and Sharman 2008). Because of these limitations, 
TABLE 1. Model grid spacing and number of vertical levels. D02 represents the innermost nest of S1 (i.e., D02 $=1$ parent and 1 nest), and D03 represents the innermost nest of S2-S4 (i.e., D03 = 1 parent and 2 nests).

\begin{tabular}{crcc}
\hline \hline Model & $\begin{array}{c}\text { Horizontal } \\
\text { grid spacing }\end{array}$ & $\begin{array}{c}\text { No. of } \\
\text { vertical levels }\end{array}$ & $\begin{array}{c}\text { Mean vertical } \\
\text { grid spacing } \\
\text { (7-11 km in height) }\end{array}$ \\
\hline S1 & $12 \mathrm{~km}$ (D02) & 65 & $550 \mathrm{~m}$ \\
S2 & $3 \mathrm{~km}$ (D03) & 65 & $550 \mathrm{~m}$ \\
S3 & $3 \mathrm{~km}$ (D03) & 100 & $325 \mathrm{~m}$ \\
S4 & $500 \mathrm{~m}$ (D03) & 100 & $325 \mathrm{~m}$ \\
\hline
\end{tabular}

direct comparisons of the location and timing of PIREPs will not be made with simulated EDR in this study.

The National Center for Atmospheric Research (NCAR) Turbulence Detection Algorithm (NTDA) produces 5-min 3D in situ observations of in-cloud turbulence for the contiguous United States at 15 height levels (Williams et al. 2011). The use of NTDA for turbulence verification has increased recently (Pearson and Sharman 2017) and has shown to perform well for in-cloud turbulence prediction. However, the skill of NTDA for out-of-cloud turbulence intensity has not been well tested. In addition, out-of-cloud turbulence intensity can only be determined using NTDA incloud turbulence observations. NTDA observations will not be used in this study because the focus is out-ofcloud turbulence, and therefore only PIREPs will be considered as turbulence observations.

\section{b. Model setup}

In this study, 30-h forecasts of convection in the northern Great Plains from 10 to 17 July 2015 are made using the Advanced Research WRF Model, version 3.7 (Skamarock and Klemp 2008). All simulations are initialized at 0000 UTC with ERA-Interim (http://www. ecmwf.int/en/research/climate-reanalysis/era-interim) global reanalysis data and run using Extreme Science and Engineering Discovery Environment (XSEDE) resources (Towns et al. 2014). Forecasts are then analyzed from 0600 to 0600 UTC (forecast hours 7-30). Four sets of horizontal and vertical grid spacings are used for these simulations and range from $12 \mathrm{~km}$ to $500 \mathrm{~m}$ in the horizontal (Table 1) with one-way nesting implemented. Model setup 1 (S1) is designed to be similar in resolution to the North American Model (NAM), setup 2 (S2) is similar to the operational HighResolution Rapid Refresh (HRRR) model, setup 3 (S3) is comparable to the HRRR but with a finer vertical resolution, and setup 4 (S4) will be used as the high-resolution simulations and considered to be "truth." This spectrum of grid spacings encompasses operational and research applicable model setups.
TABLE 2. Model parameterization used in simulations. The cumulus parameterization is not applicable to model setup 4.

\begin{tabular}{lccr}
\hline \hline & \multicolumn{3}{c}{ Model setup } \\
\cline { 2 - 4 } Parameterizations & 1 & 2 & 3 \\
\hline Microphysics & \multicolumn{2}{c}{ WDM6 } \\
PBL & MYJ \\
Surface layer & MM5 similarity \\
Land surface & Noah \\
Shortwave & Dudhia \\
Longwave & RRTM & \\
Cumulus & Kain-Fritsch(D01 and D02) & - \\
\hline
\end{tabular}

Parameterizations for all of the simulations are provided in Table 2. The model top in all simulations is set to $10 \mathrm{hPa}$ (approximately $30 \mathrm{~km}$ ), and a $10-\mathrm{km}$-deep damping layer is used at the model top. The model domains for S1-S3 remain unaltered and encompass the same geographical area for all eight simulation periods. For S4, the model domain varies with simulation period based on the known location of convection from observations in order to limit the computational costs (i.e., the model domain for each simulation period does not cover the same geographical area). The model domain for each simulation is provided in Figs. 1 and 2. Section 3 will highlight findings from three simulation days on which the convective types included linear features, weak and intense isolated convection, and decaying mesoscale convective systems.

\section{c. Eddy dissipation rate}

Turbulence intensity is estimated by computing EDR from turbulent kinetic energy (TKE) of each simulation. TKE is obtained from the subgrid planetary boundary layer (PBL) parameterization, which in this study is the Mellor-Yamada-Janjić (MYJ) scheme. The calculation of TKE is derived from the vertical component of velocity only (Janjić 1994). At 500-m horizontal grid spacing, it is possible that a portion of the TKE is resolved. However, for consistency in approach across all simulations, this "resolved" component of TKE is ignored in these simulations. Note that the analysis in the subsequent sections shows that simulations with 500-m grid spacing (S4) predicted more severe turbulence than the other simulations even without this component. EDR is a popular aviation turbulence metric that is not dependent on physical aircraft variables such as type, weight, and speed (Poellot and Grainger 1991; Emanuel et al. 2013). EDR can be calculated using various inflight data such as vertical acceleration, true airspeed, and three-dimensional winds (Poellot and Grainger 1991; Cornman et al. 1995; Emanuel et al. 2013; Ahmad and Proctor 2012). The calculation for EDR used in this study is 


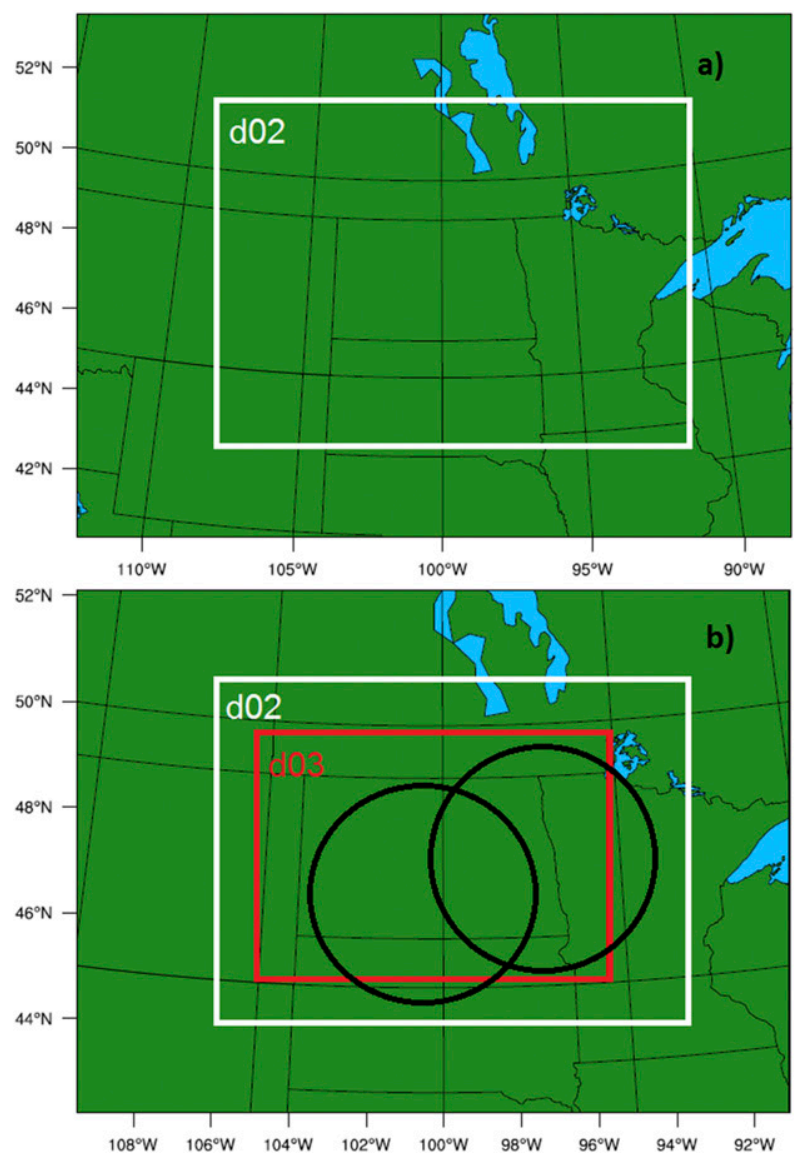

FIG. 1. Model domain for (a) model setup S1 and (b) model setups S2 and S3. D02 represents the innermost nest of model setup S1, and D03 represents the innermost nest of model setups S2 and S3. The black circles represent the Mayville and Bismarck, North Dakota, radars.

$$
\mathrm{EDR}^{1 / 3}=\left(\frac{\mathrm{TKE}^{3 / 2}}{L}\right)^{1 / 3}
$$

where TKE is the turbulent kinetic energy $\left(\mathrm{m}^{2} \mathrm{~s}^{-2}\right)$ and $L$ is a length scale (Ahmad and Proctor 2012). Ahmad and Proctor (2012) investigated the accuracy of boundary layer turbulence intensity when using a length scale $L$ that is dependent on the model PBL scheme. Their study concluded that EDR at $40 \mathrm{~m}$ above ground level (AGL) when calculated using a model-predicted $L$ was less accurate than a constant $L$ of $336 \mathrm{~m}$. Other constant length scales were evaluated but also found to be less accurate. Many have continued to improve the validity of the length scale from model output, but most progress has been made for boundary layer turbulence estimations (MuñozEsparza et al. 2016; Sauer et al. 2016). There is much uncertainty in how length scales estimated by a PBL scheme relates to a length scale in the upper atmosphere. In this study,

$$
L=\Delta x \Delta y \Delta z^{1 / 3},
$$

where $\Delta x$ is the horizontal resolution in the $x$ direction, $\Delta y$ is the horizontal resolution in the $y$ direction, and $\Delta z$ is the vertical resolution in the $z$ direction (Schumann 1991; Sharman et al. 2012).

Atmospheric turbulence is commonly defined as light, moderate, and severe based on the cubed root of EDR $\left(\mathrm{m}^{2 / 3} \mathrm{~s}^{-1}\right.$; Table 3 ; Lane et al. 2012). This study will use thresholds corresponding to Lane et al. (2012). Recently, new EDR values have been proposed (Sharman et al. 2014; Sharman and Pearson 2017; Pearson and Sharman 2017) based on climatological PIREPs and various sources including the Global Turbulence Guidance (GTG) product. This study will mainly discuss the former thresholds but provide both thresholds in figures to demonstrate the various intensities based on which thresholds are used.

\section{d. Ellrod index}

The Ellrod index is a turbulence intensity (TI) metric used for aviation turbulence avoidance. There are two different methods of calculating the Ellrod index, TI1 and TI2.

$$
\mathrm{TI} 1=\mathrm{VSH} \times \operatorname{DEF}\left(\mathrm{s}^{-2}\right),
$$

where VSH is the vertical wind shear and DEF is the deformation of the horizontal components.

$$
\mathrm{TI} 2=\mathrm{VSH} \times(\mathrm{DEF}+\mathrm{CON})\left(\mathrm{s}^{-2}\right)
$$

where $\mathrm{CON}$ is the convergence of the horizontal components (Ellrod and Knapp 1992). The U.S. Air Force Weather Agency (AFWA) includes TI2 as part of their turbulence forecast output at seven altitude ranges, from $1.5 \mathrm{~km}$ extending to $12.7 \mathrm{~km}$ (Creighton et al. 2014). TI 2 values of $4-8$ represent clear-air turbulence intensities of light to moderate, values of $8-12$ represent turbulence intensities of moderate, and values greater than 12 represent severe turbulence. TI2 generated from the NAM simulations are also provided by the Aviation Weather Center as turbulence guidance and uses these same thresholds. There are two limitations with the thresholds used for TI2, the first being the verification of the empirical values. Empirical values were correlated to only clear-air turbulence PIREPs and convectively induced turbulence PIREPs were neglected (Ellrod and Knapp 1992). Second, the 

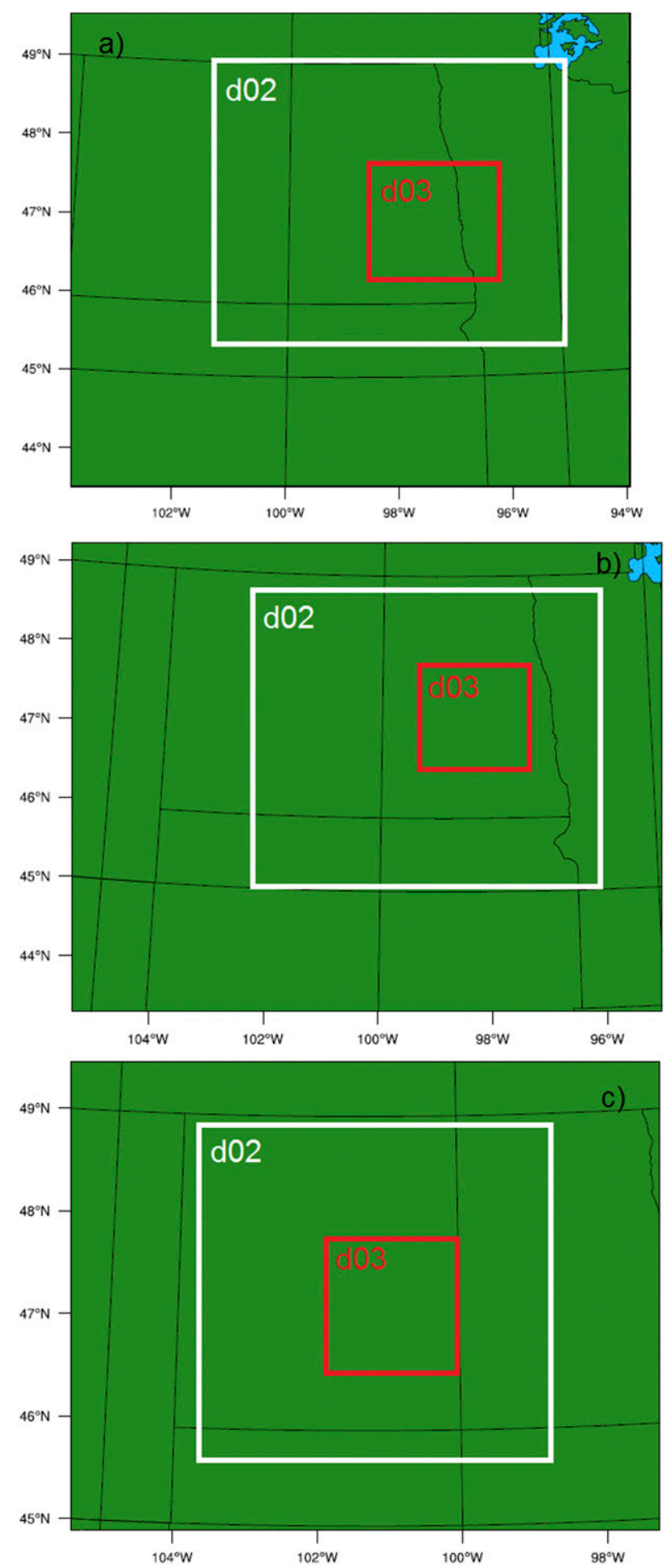

FIG. 2. Model domain for model setup S4 on (a) 12, (b) 13, and (c) 15 Jul 2015.

empirical values were derived from models designed with grid spaces greater than $50 \mathrm{~km}$ (Ellrod and Knapp 1992). This research will calculate the Ellrod index and examine the distribution of numerical
TABLE 3. The TI as determined from the cubed root of EDR ( $\varepsilon$; Lane et al. 2012; Sharman and Pearson 2017).

\begin{tabular}{lcc}
\hline \hline & \multicolumn{2}{c}{$\varepsilon^{1 / 3}\left(\mathrm{~m}^{2 / 3} \mathrm{~s}^{-1}\right)$} \\
\cline { 2 - 3 } \multicolumn{1}{c}{ TI } & Lane et al. (2012) & $\begin{array}{c}\text { Sharman and Pearson (2017) } \\
\text { median }\end{array}$ \\
\hline Light & $0.1-0.3$ & 0.01 \\
Moderate & $0.3-0.5$ & 0.22 \\
Severe & $0.5-0.7$ & 0.47 \\
\hline
\end{tabular}

values out of cloud for each simulation using the original thresholds.

\section{e. Lateral avoidance}

Current FAA thunderstorm guidelines are implemented to reduce the frequency of thunderstorm hazard encounters by aircraft. These guidelines include a lateral avoidance of $20 \mathrm{mi}$ from a thunderstorm. In this study, lateral avoidance will be examined by creating range circles around simulated convection. The following discussion will describe this methodology. Echo-top height is used as a proxy for convection and considered in cloud. An 18-dBZ threshold for simulated radar reflectivity is used to determine the echotop height. Individual grid cells with echo-top heights (ET) greater than $8 \mathrm{~km}$ in altitude are masked out within the domain. Radius ranges of 10, 20, and $50 \mathrm{mi}$ $(16.1,32.2$, and $80.5 \mathrm{~km})$ are calculated for each grid cell that has ETs $\geq 8 \mathrm{~km}$ (Fig. 3). Turbulence grid cells within these radius ranges are out-of-cloud if there is no ET greater than $8 \mathrm{~km}$ in the same location. Out-ofcloud turbulence will be analyzed within 10, 20, and $50 \mathrm{mi}$ of convection. Out-of-cloud turbulent grid cells within the lateral distances of convection are examined at 8,10 , and $12 \mathrm{~km}$ in altitude (common cruising altitudes of commercial aircraft).

\section{Results}

This section highlights findings from three simulation days (12, 13, and 15 July 2015) from 0600 to 0600 UTC of the forecast period. These days were selected for analysis because convection was severe with numerous storm reports and pilot reports recorded in the North Dakota region. The convective types observed during these analysis times included linear features, weak and intense isolated convection, and decaying mesoscale convective systems. A detailed overview of the S4 simulation and a comparison with observed storm characteristics is first presented, as S4 will be considered to be truth in the model comparisons. The other model configurations are then compared with S4 

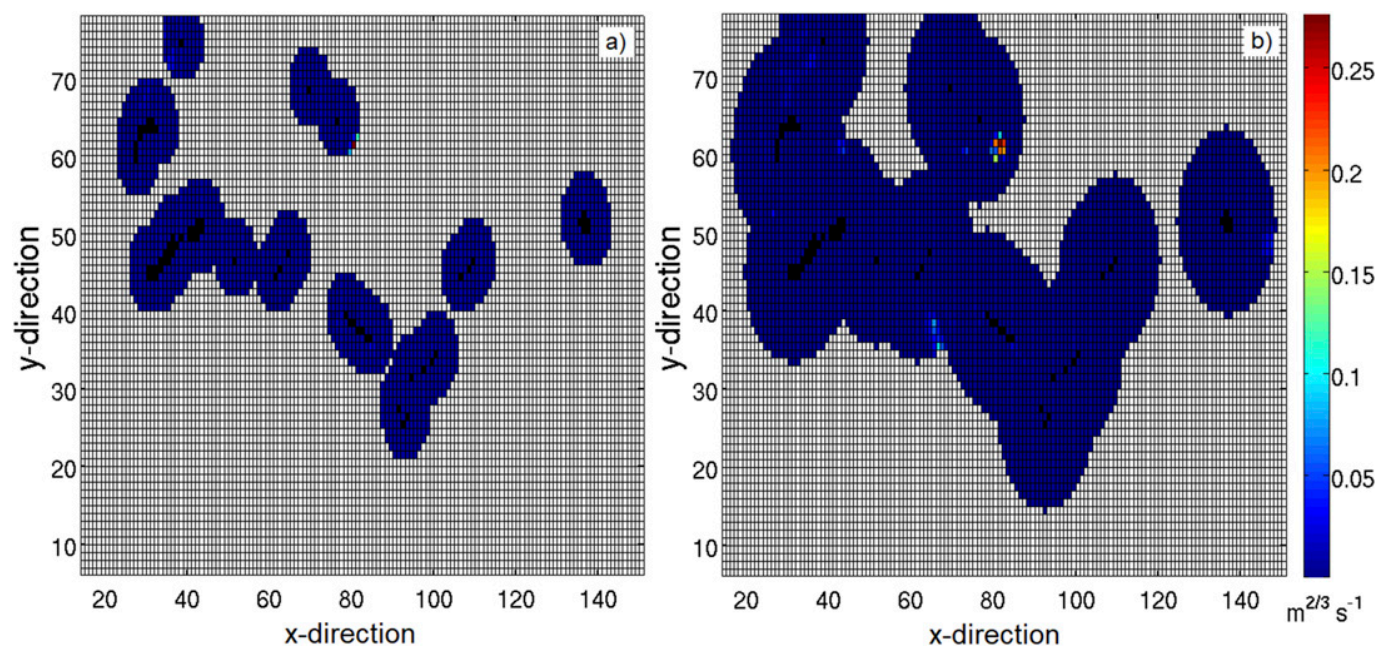

FIG. 3. Schematic depicting masking methodology for determining the turbulence distribution (color bar; $\mathrm{m}^{2 / 3} \mathrm{~s}^{-1}$ ) within various distances from convective cores at various altitudes. Black grid cells represent echo-top heights $\geq 8 \mathrm{~km}$; blue-colored grid cells represent distances of (a) 10 and (b) 20 mi around ET cores.

to assess the impacts of resolution on simulated turbulence.

\section{a. Storms observed}

\section{1) 12 JULY 2015 (0600 UTC 12 JULY-0600 UTC 13 JULY)}

Convection on 12 July was severe and produced large hail, severe winds, and several tornadoes (EF0-EF2 on the enhanced Fujita scale) in the eastern portion of North Dakota (ND) and western Minnesota (MN). Storms began as intense individual cells in the northeast and southeast portion of ND around 2000 UTC. Near 2200 UTC the convection merged into two large convective regions with radar reflectivity values at $1-\mathrm{km}$ AGL exceeding $55 \mathrm{dBZ}$ along the ND-MN border (Fig. 4a). The northern complex began to weaken around 0100 UTC 13 July while the southern complex continued to strengthen until 0200 UTC. Maximum echo-top (ET; $\geq 18 \mathrm{dBZ}$ ) heights are used in this study as a proxy for convective strength. ETs are determined from level-III radar data. Observed ETs for this convective period exceeded $15 \mathrm{~km}$ in both the northern and southern convective segments (Fig. 5a). There were 27
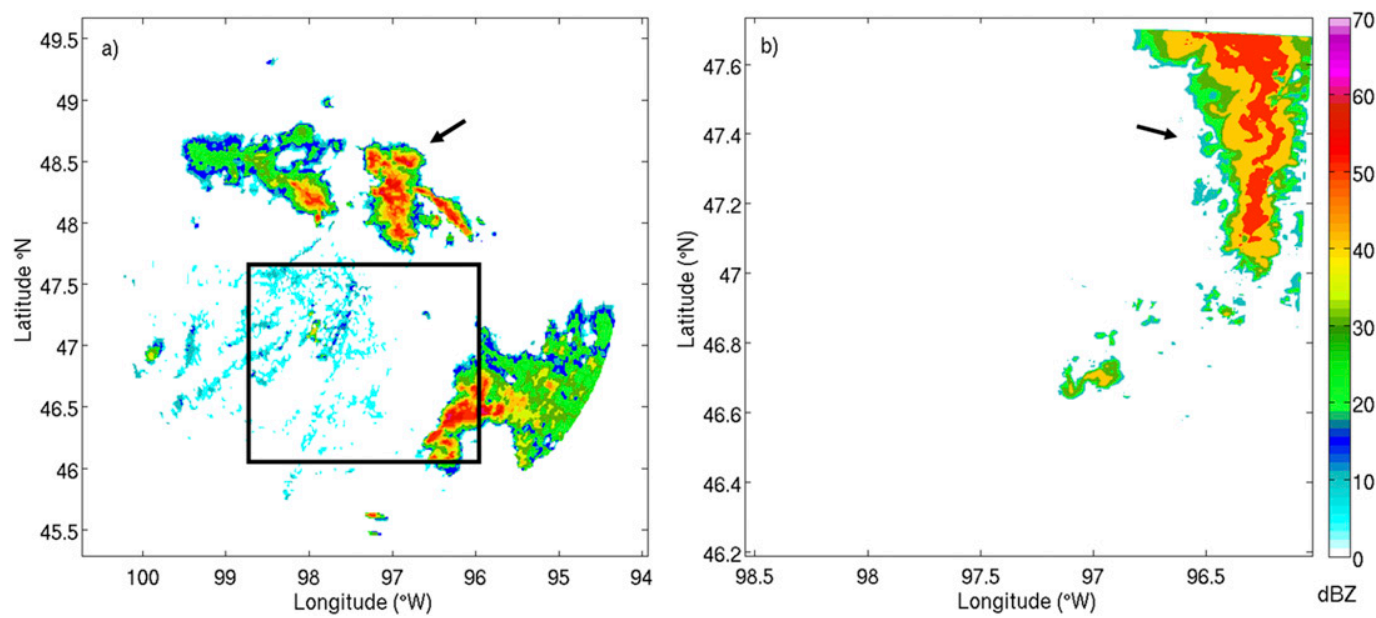

FIG. 4. (a) Observed Mayville radar reflectivity ( $0.5^{\circ}$ elevation angle) at 2155 UTC 12 Jul and (b) simulated 1-km AGL radar reflectivity at 0200 UTC $13 \mathrm{Jul}$ for S4 (forecast initialized at $0000 \mathrm{UTC} 12 \mathrm{Jul}$ ). The black box in (a) represents the model domain in (b). Black arrows are included to point out the northern complex discussed in section 3b. See Fig. 2a for the complete model domain. 


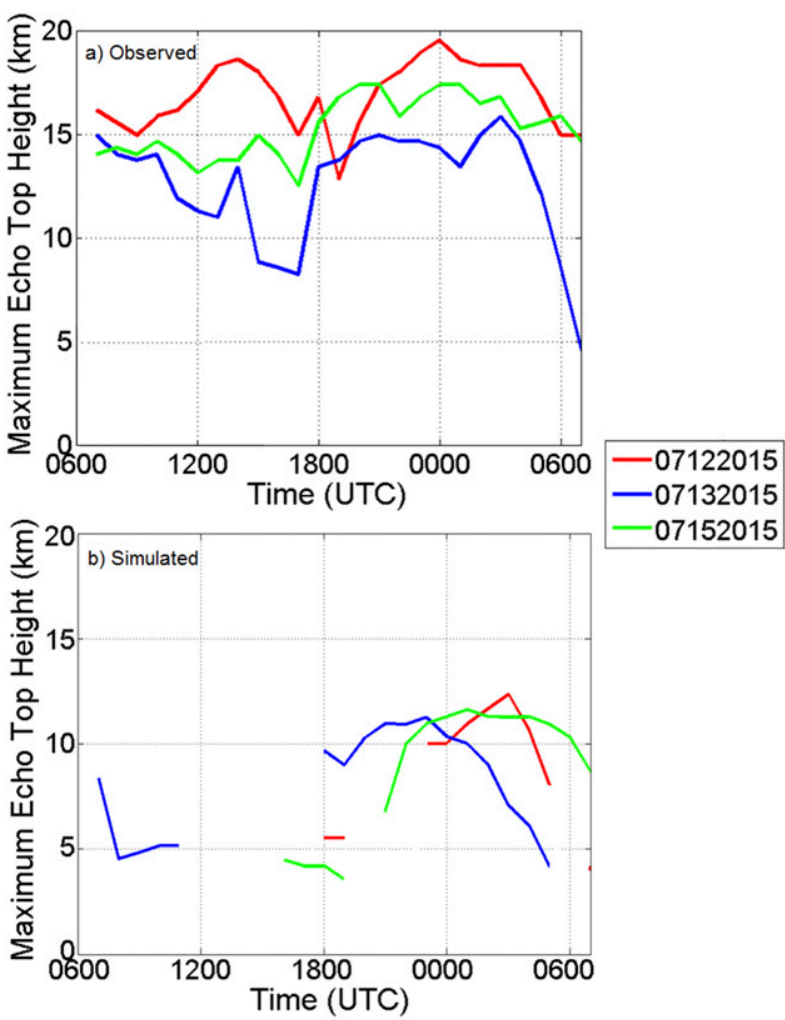

FIG. 5. Maximum echo-top heights (km) (a) observed by Mayville and Bismarck radar and (b) simulated by $\mathrm{S} 4$.

PIREPs from 0600 UTC 12 July to 0600 UTC 13 July, with 5 reports classified as light and 22 as moderate. Of the 27 PIREPs, 24 PIREPs were above $8 \mathrm{~km}$ at the time of the report. The majority of the encounters were located near the ND-MN border in the afternoon (Fig. 6) and were out of cloud. The EDR values of these reports when converted using Sharman et al. (2014) methodology varied between 0.18 and $0.27 \mathrm{~m}^{2 / 3} \mathrm{~s}^{-1}$ (i.e., moderate intensity).

\section{2) 13 July 2015 (0600 UTC 13 July-0600 UTC 14 JULY)}

Convection on 13 July was nonsevere and mainly isolated cells that formed from weak frontal boundaries in the northern region of ND. These cells began to develop around 1800 UTC and dissipated near 0100 UTC (Fig. 7a); 1-km AGL reflectivity values of these convective cells exceeded $50 \mathrm{~dB} Z$. Observed ETs extended past $14 \mathrm{~km}$ in altitude in multiple isolated cells west of the ND-MN border around 2000 UTC but began decreasing in altitude shortly after 2200 UTC (Fig. 5a). From 0600 UTC 13 July to 0600 UTC 14 July, pilots reported nine turbulence encounters in the ND-MN-South Dakota (SD) region, all of which were moderate intensity. Eight of the nine were above $8 \mathrm{~km}$ and out of cloud.

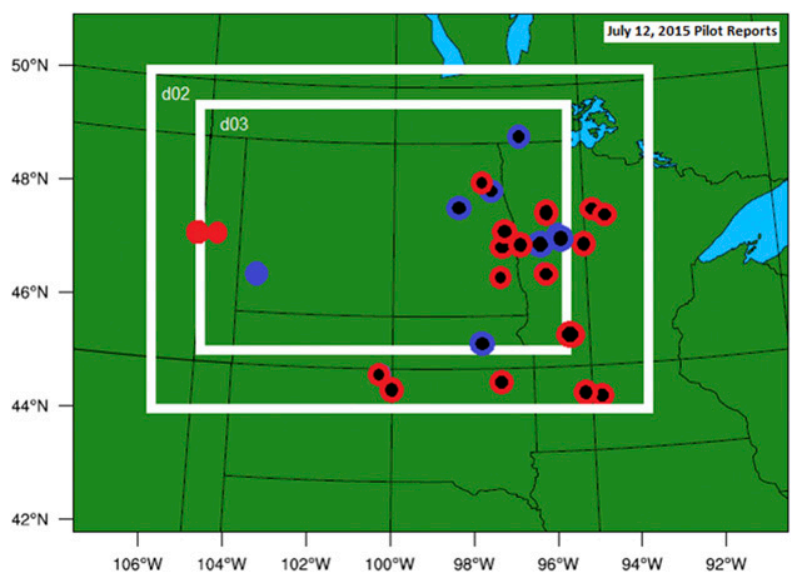

FIG. 6. PIREPs of turbulence occurring on 12 Jul 2015 within the S2-S3 model domain (innermost white box represents the 3-km domain). Blue (red) circles represent light (moderate) turbulence reports. Black dots within the circles indicate the report was made when the aircraft was $>8 \mathrm{~km}$ in altitude.

\section{3) 15 July 2015 (0600 UTC 15 July-0600 UTC 16 JULY)}

Convection that occurred on 15 July produced hail greater than $1 \mathrm{in}$. in diameter and three severe wind reports. Convection began overnight (0600 UTC, 0100 local time) in western ND as large isolated cells that propagated into central ND and organized into a weak convective complex by 1300 UTC. Radar reflectivity values were less than $55 \mathrm{dBZ}$ at $1-\mathrm{km}$ AGL. The complex formed a bowing segment near 1800 UTC in the southeast region of ND with radar reflectivity values exceeding $55 \mathrm{~dB} Z$. This bowing feature dissipated by 2300 UTC in western MN, while more intense isolated convection developed in the western portion of ND (Fig. 8a). At 0200 UTC a strong linear feature with radar reflectivity values exceeding $60 \mathrm{~dB} Z$ was present in northwest ND (Fig. 9a) and $2 \mathrm{~h}$ later weakened into a stratiform-dominant feature. Observed ETs exceeded $16 \mathrm{~km}$ in altitude in western ND near 1800 UTC (Fig. 5a). On 15 July there were 10 reports of turbulence, 8 of which were moderate intensity. All of the reports of moderate turbulence were above $8 \mathrm{~km}$ in altitude and out of cloud.

\section{b. S4 turbulence}

Convection simulated by $\mathrm{S} 4$ for the three simulation days was generally accurate in morphology but often inaccurate in intensity and timing. For example, the morphology of a simulated isolated convective segment in the northern region of the S4 domain was very similar to observations on 12 July (Fig. 4b), but was lagging in time by approximately $4 \mathrm{~h}$ and was located farther 

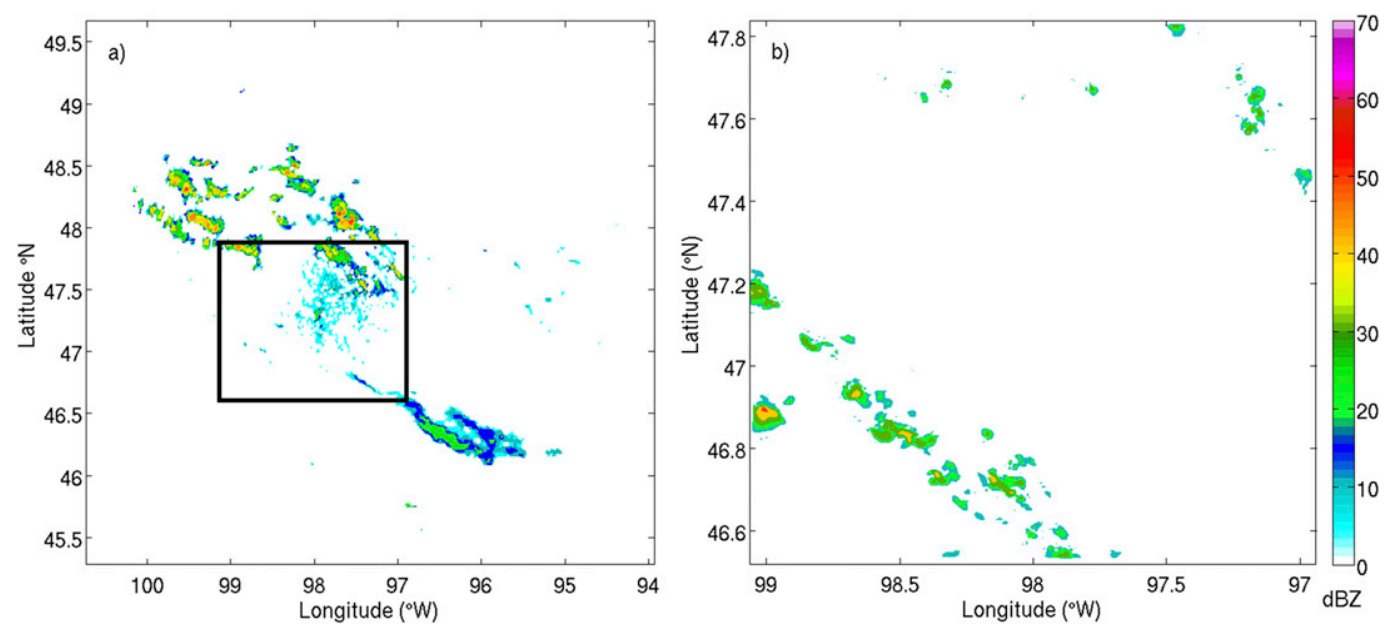

FIG. 7. (a) Observed Mayville radar reflectivity (0.5 elevation angle) at 1925 UTC 13 Jul and (b) simulated 1-km AGL radar reflectivity for 1900 UTC 13 Jul for S4 (forecast initialized at 0000 UTC 13 Jul). The black box in (a) represents the model domain in (b). See Fig. $2 b$ for the complete model domain.

south in latitude. In addition, S4 simulated ETs above $11 \mathrm{~km}$ after 2200 UTC with a maximum of approximately $12 \mathrm{~km}$ after 0200 UTC (Fig. 5b), but observed ETs were greater than $15 \mathrm{~km}$. For 13 July, S4 simulated the correct type of convection (isolated), developed and dissipated simulated convection in the same time period as observed convection, but had weaker reflectivity intensity at $1 \mathrm{~km}$ AGL (Fig. 7b). Simulated vertical depth of convection on 13 July was also lower than observed (Figs. 5b). These results were also consistent for simulated convection on 15 July (correct morphology and timing but shallower depth; Figs. 8b, 9b, and 5b). Previous studies have shown that the microphysical scheme implemented can influence simulated ET height. Stephan and Alexander (2014) compared ETs and cloud tops for the WRF double-moment 6-class microphysics scheme (WDM6) with other microphysical schemes. Relative to the Morrison or Thompson scheme, WDM6 had fewer high ETs but similar cloud-top heights. The lower ETs were likely related to lower columnintegrated ice amounts. Although the vertical depth of simulated convection was substantially less than observations indicated, turbulence magnitude will be evaluated and compared with PIREPs.

The Ellrod index is examined in the $\mathrm{S} 4$ domain at $8-, 10-$, and $12-\mathrm{km}$ altitudes. During the simulation period, the minimum nonzero values of the Ellrod index exceed the severe threshold of 12 by an order of magnitude and cover large portions of the domain. A direct comparison of the Ellrod index and EDR predicted by
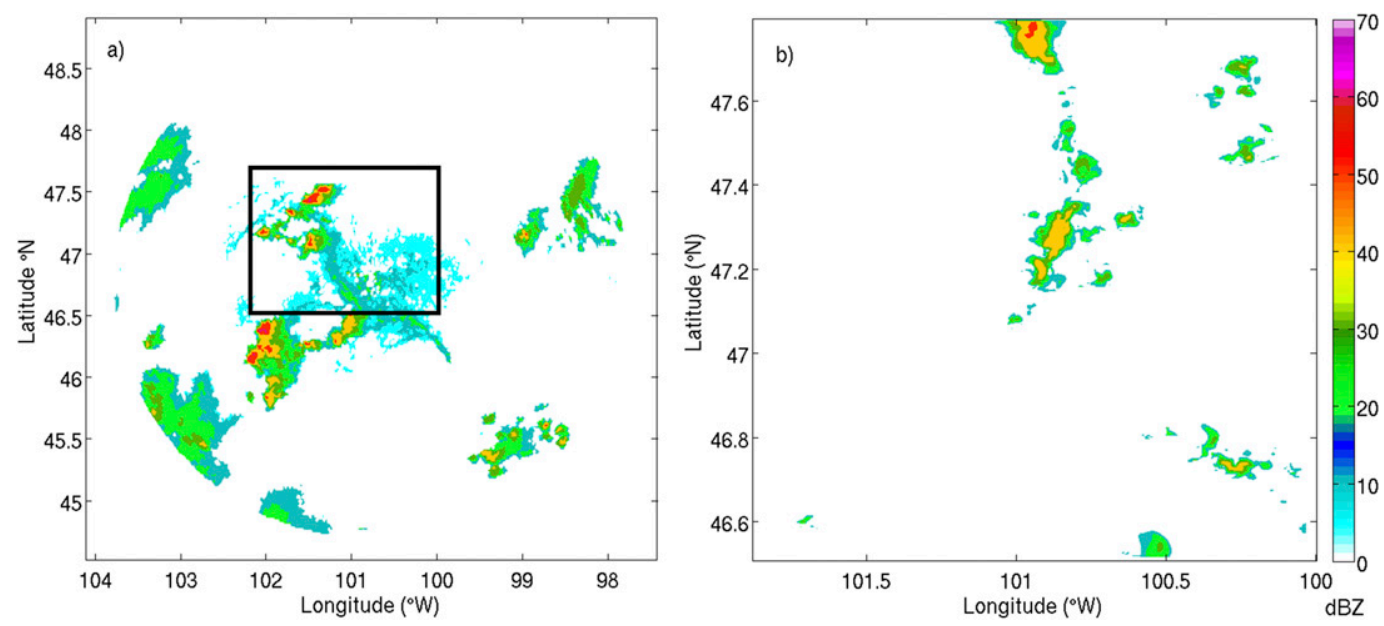

FIG. 8. As in Fig. 7, but for Bismarck at 2325 UTC 15 Jul and (b) at 0000 UTC 16 Jul for S4 (forecast initialized at 0000 UTC $15 \mathrm{Jul})$. See Fig. 2c for the complete model domain. 

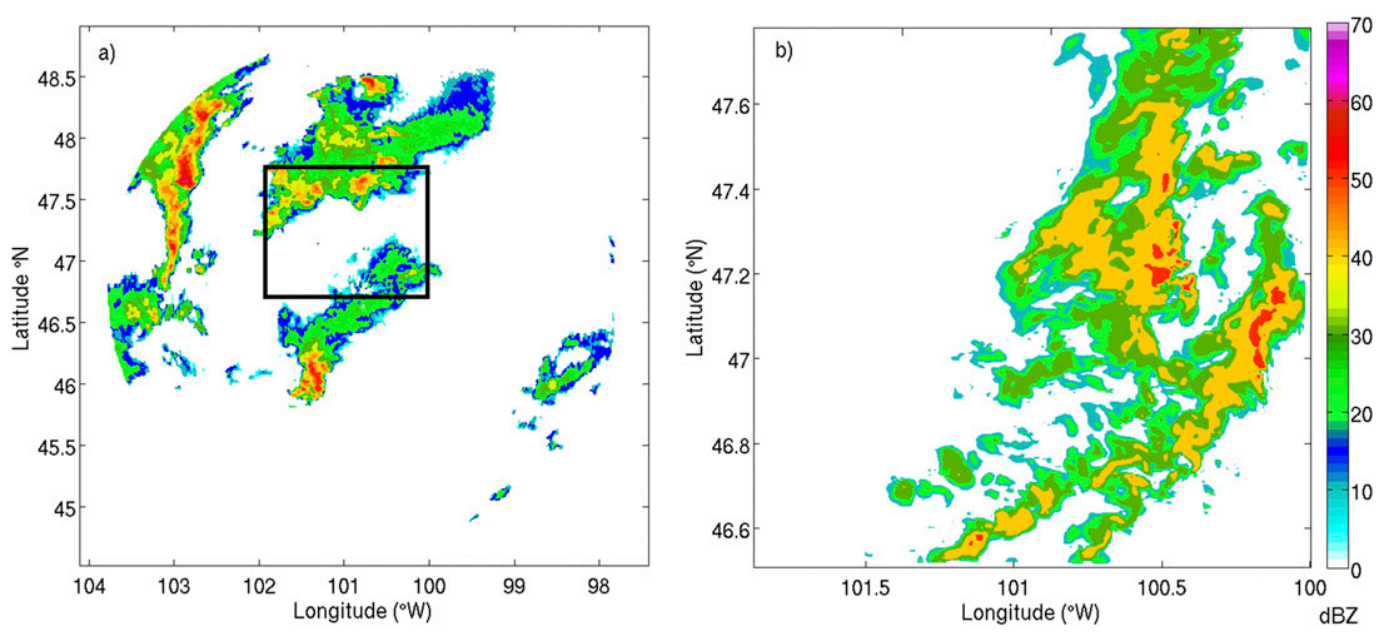

FIG. 9. As in Fig. 8, but at 0225 UTC 16 Jul and (b) at 0200 UTC 16 Jul for S4 (forecast initialized at 0000 UTC $15 \mathrm{Jul}$ ).

S4 at $8 \mathrm{~km}$ in altitude at $0200 \mathrm{UTC}$ is provided in Fig. 10. This comparison demonstrates a large areal coverage of severe turbulence estimated by the Ellrod index (blue color contour $=$ severe) and a smaller areal coverage of moderate turbulence estimated by EDR (purple color contour $=$ moderate). This overestimation of turbulence magnitude and occurrence by the Ellrod index was consistent through the entire simulation period, for all
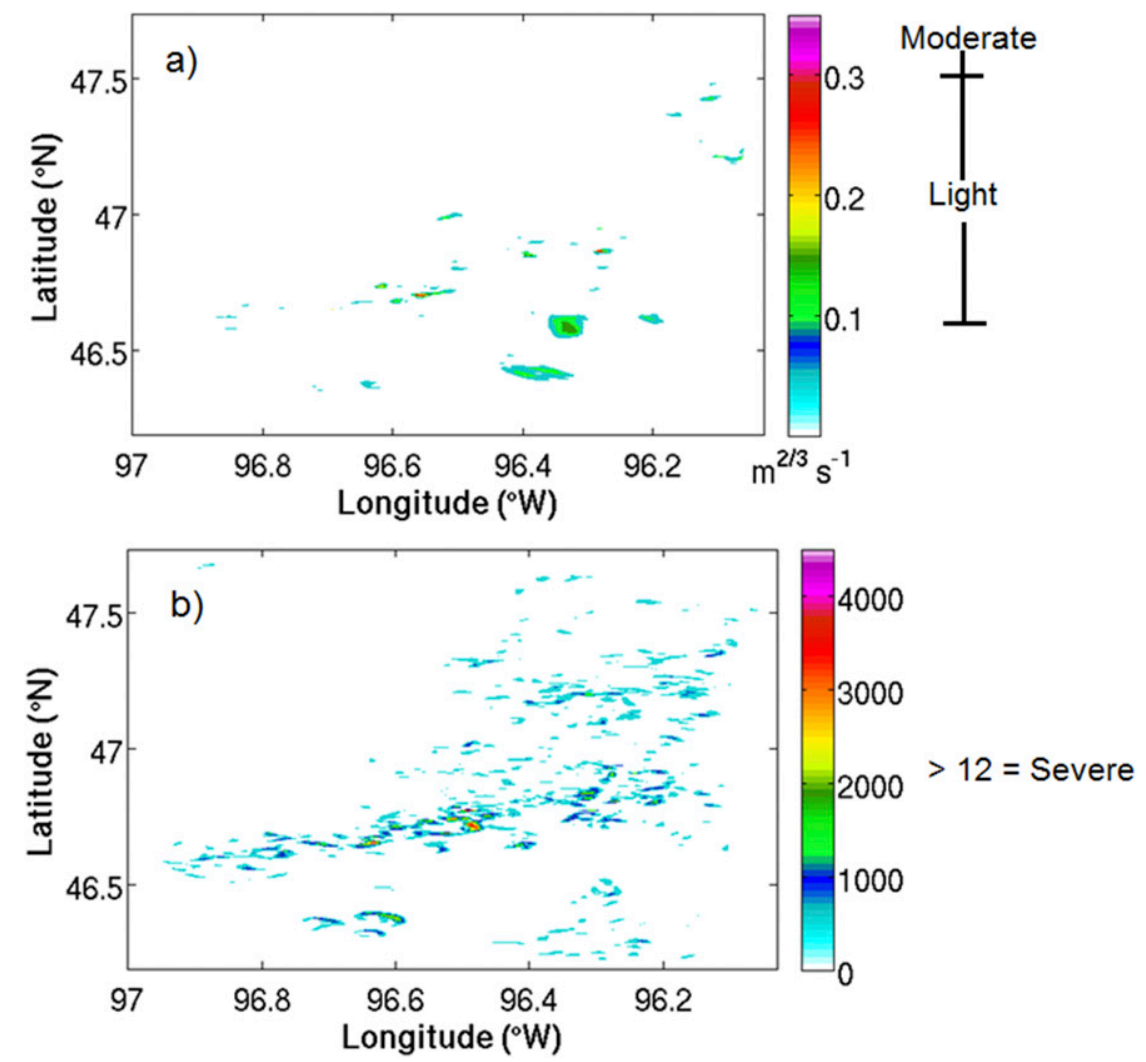

FIG. 10. (a) EDR [magnitudes indicated using Lane et al. (2012)] and (b) Ellrod index values at $8 \mathrm{~km}$ in altitude predicted from S4 at 0200 UTC 13 Jul 2015 (from 0000 UTC initialized forecast on $12 \mathrm{Jul}$ ). All colored regions in (b) are traditionally classified as "severe." 


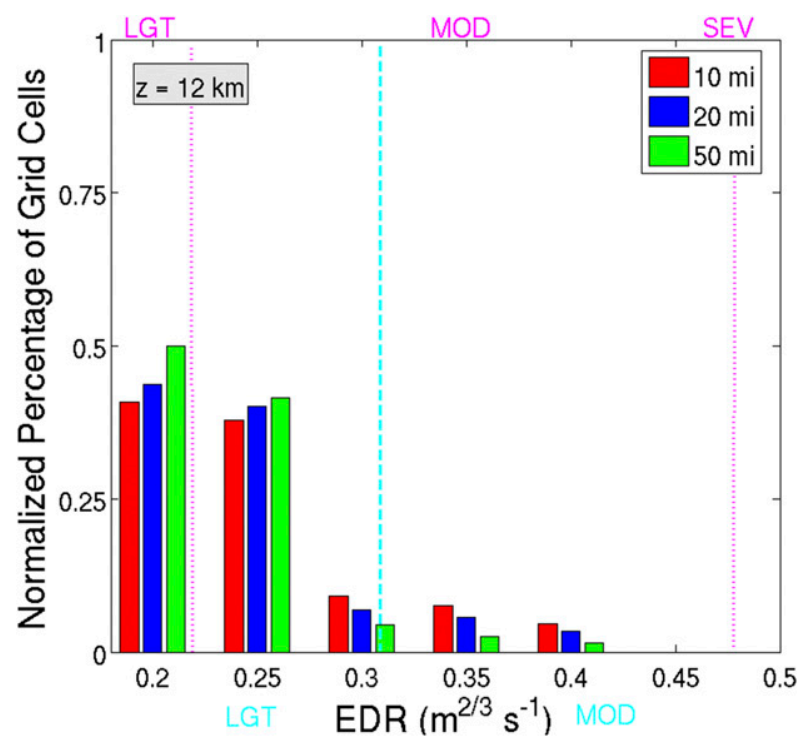

FIG. 11. The 12-km normalized out-of-cloud EDR distribution $\geq$ $0.2 \mathrm{~m}^{2 / 3} \mathrm{~s}^{-1}$ (No. of turbulent grid cells within bin divided by all grid cells with turbulence $\geq 0.2 \mathrm{~m}^{2 / 3} \mathrm{~s}^{-1}$ ) for $12 \mathrm{Jul} 2015$ within 10,20 , and $50 \mathrm{mi}$ of convective cores with echo-top heights $\geq 8 \mathrm{~km}$ for S4. Dashed (cyan) and dotted (purple) vertical lines represent turbulence intensities based on Lane et al. (2012) and Sharman et al. (2014), respectively.

heights and all lateral distances away from convection. This analysis highlights the resolution sensitivity of the Ellrod index at higher model resolutions. Upon further investigation, the vertical wind shear term in the calculation of the Ellrod index was found to have the largest impact on the magnitude of turbulence. At this time the Ellrod index is not a useful measure across different model resolutions unless a resolution-scale-dependent threshold were developed. The empirical values originally derived for the Ellrod index are not applicable to model setups with finer grid spacing without calibration or reverification of new values to PIREPs. The Ellrod index similarly overestimated turbulence at the $3-\mathrm{km}$ resolution (not shown; see also Barber 2015). Because of the extreme resolution sensitivity of the Ellrod index, the remainder of this study will not discuss the Ellrod index.

Out-of-cloud EDR values are examined within 10, 20, and $50 \mathrm{mi}$ from convection at 8,10 , and $12 \mathrm{~km}$ in altitude (12-km analysis provided in Fig. 11) on 12 July. At $12 \mathrm{~km}$ in altitude, more of the turbulent grid cells were light in magnitude within $50 \mathrm{mi}$ of convection and more of the turbulent grid cells were moderate in magnitude within $10 \mathrm{mi}$ of convection. Similar relationships in turbulence intensity and distance are seen at both 8 and $10 \mathrm{~km}$ in height. Although there was a higher percentage of turbulent grid cells with moderate intensity within $10 \mathrm{mi}$

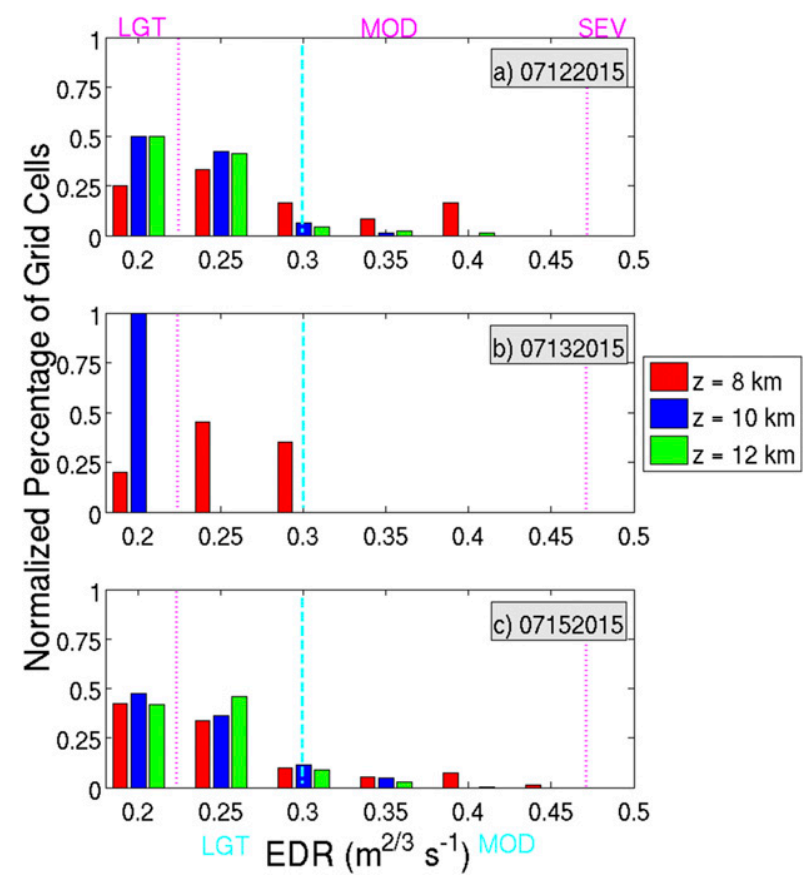

FIG. 12. Similar to Fig. 11, but within $50 \mathrm{mi}$ for three altitudes on (a) 12, (b) 13, and (c) 15 Jul 2015.

away from convection, turbulence within $50 \mathrm{mi}$ of convection is important to forecast because it is farther than the $20 \mathrm{mi}$ lateral distance avoidance guideline set by the FAA. Because of this finding, turbulence within $50 \mathrm{mi}$ of convective cores will be discussed hereinafter.

\section{1) 12 July 2015 (0600 UTC 12 July-0600 UTC JULY 13)}

Figure 12a provides the EDR values within $50 \mathrm{mi}$ of convective cores with ETs greater than $8 \mathrm{~km}$ in altitude. The lowest EDR values had the greatest areal coverage, indicating that there is a significant amount of area experiencing light turbulence. The highest EDR values were predicted at 8 and $12 \mathrm{~km}$ in altitude for S4, below and above the maximum ET. Although the areal coverage of the highest EDR values was small, the prediction of these values is crucial. In relationship to the PIREPs on 12 July, turbulence estimated by EDR was the same magnitude as the PIREPs: light and moderate intensity above $8 \mathrm{~km}$.

Although simulated convection was lagging in time and predicted ETs significantly lower than observations, estimated turbulence magnitude was similar to observations. In a real-time operational setting (assuming the S4 simulation could be performed in a timely manner), moderate turbulence caused by deep convection would have been forecast in the ND area at altitudes near where commercial aviation had 


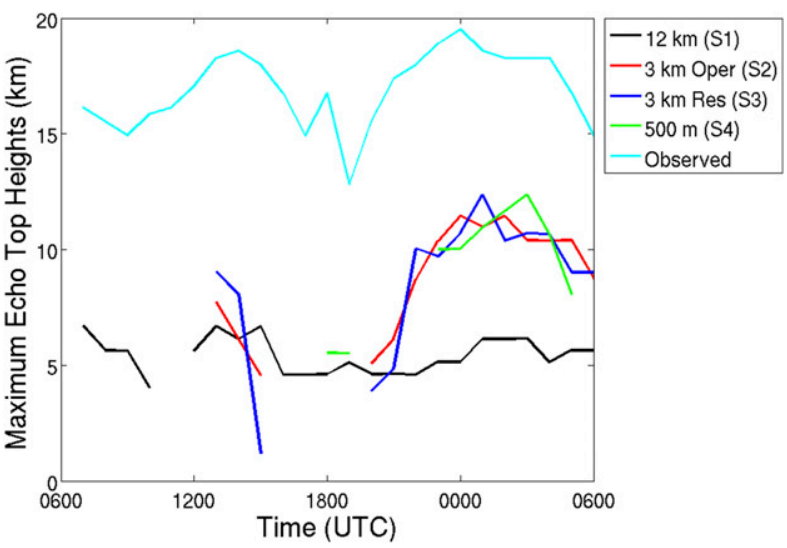

FIG. 13. Maximum echo-top heights $(\mathrm{km})$ forecast by S1-S4 and estimated by radar on 12 Jul 2015 beginning at 0600 UTC.

reported. S4 could have been utilized in an operational setting for the prediction of turbulence.

\section{2) 13 July 2015 (0600 UTC 13 JuLY-0600 UTC JULY 14)}

The distribution of out-of-cloud EDR values within 50 mi of convection on 13 July is significantly narrower than on 12 July (Fig. 12b) and the majority of EDR values are less than $0.1 \mathrm{~m}^{2 / 3} \mathrm{~s}^{-1}$. The maximum EDR value predicted by $\mathrm{S} 4$ was $0.3 \mathrm{~m}^{2 / 3} \mathrm{~s}^{-1}$ and occurred at $8 \mathrm{~km}$ in altitude. At both 10 and $12 \mathrm{~km}, \mathrm{~S} 4$ did not predict any EDR values greater than $0.25 \mathrm{~m}^{2 / 3} \mathrm{~s}^{-1}$. Again, the likelihood of encountering light turbulence is far greater than experiencing moderate turbulence, especially below $10 \mathrm{~km}$ in altitude. $\mathrm{S} 4$ did predict moderate turbulence, although it was at a lower altitude than the majority of PIREPs indicated.

For this case day, convective morphology (isolated) and timing was well predicted by S4. However, the storm intensity was too weak, as evidenced by both reflectivity and echo-top heights. This is the likely reason that S4 in general underpredicted the turbulence intensity. While at times turbulence intensity was correct, the predicted altitude was too low. This suggests the S4 simulations of turbulence have difficulty with convection that is isolated, is less intense, and has a shorter lifespan.

\section{3) 15 July 2015 (0600 UTC 15 JULY-0600 UTC JULY 16)}

The distribution of out-of-cloud EDR values forecast by S4 on 15 July again shows mostly light turbulence at 10 and $12 \mathrm{~km}$ (Fig. 12c). This suggests a higher likelihood of aircraft encountering lower-intensity turbulence near convection because of wide areal coverage. The maximum EDR values predicted by S4 are at both 12 and $8 \mathrm{~km}$ in altitude. Moderate turbulence was predicted by

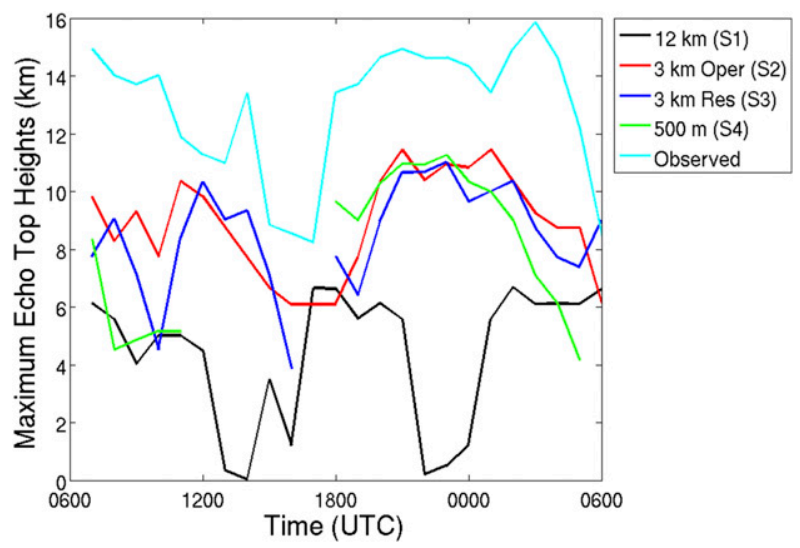

FIG. 14. As in Fig. 13, but for 13 Jul 2015.

S4 at 8,10 , and $12 \mathrm{~km}$, which agrees with observed pilot reports of turbulence. The usage of S4 in a real-time operational setting would have been beneficial, as simulated radar reflectivity at $1 \mathrm{~km}$ in altitude was comparable to observed radar reflectivity and the morphology of convection was similar to observations. Once again, the convective depth was lower than observations. However, the prediction of turbulence intensity and location did not seem to be directly affected by lower simulated ETs.

\section{c. Effects of varying resolution on turbulence}

To examine the effects of horizontal resolution on predicted turbulence, S4 will be compared with S1, S2, and S3, treating S4 as truth. Figures 13-15 provide the maximum ETs for each model setup for 12, 13, and 15 July. Important features from this analysis are the relatively low ETs for $\mathrm{S} 1$, which never exceeded $7 \mathrm{~km}$ on both 12 and 13 July. Weak convection that does not extend far in the vertical is less of a hazard for aviation operations flying above $8 \mathrm{~km}$ in altitude. The weak convection and low ETs simulated from S1 highlight that coarse horizontal model resolution, such as the $12-\mathrm{km}$ grid spacing used here, is not appropriate for the calculation of eddy dissipation rates because of the significant underprediction of convection and convective depth. Therefore, S1 will not be discussed hereinafter. However, the use of indices that are calibrated for largescale conditions could still be applied at coarser resolutions, similar to indices utilized in the Graphical Turbulence Guidance product (Sharman et al. 2006) from the Rapid Refresh products. The setups with higher vertical resolution achieved ETs $>12 \mathrm{~km}$ on 12 July, suggesting that higher vertical resolution is important for accurately predicting the convective depth of linear convective features and in turn turbulence. However, on 13 and 15 July, the relationship between maximum ETs and vertical model resolution is less 


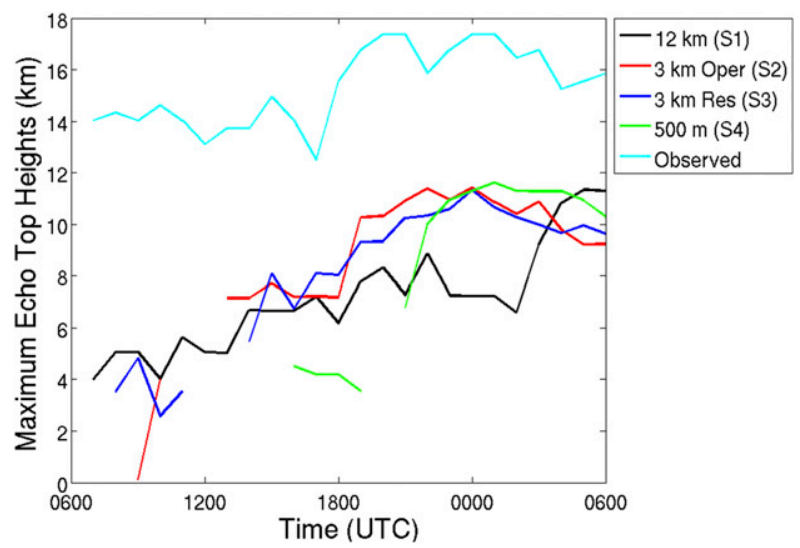

FIG. 15. As in Fig. 13, but for 15 Jul 2015.

apparent, especially on $15 \mathrm{July}$. It is possible that model resolution in the vertical has greater influence on the strength of simulated isolated convection and is less important for convection that has stronger dynamical forcing, such as organized mesoscale systems that are severe in strength, extensive in areal coverage, and long lasting, or convection that is forced by synoptic frontal boundaries.

The examination of out-of-cloud EDR values from 12 July within $50 \mathrm{mi}$ from convection at 8,10 , and $12 \mathrm{~km}$ in altitude for S2 and S3 demonstrates that lower EDR values have the greatest areal coverage (for both normalized and raw area values; all further results discuss normalized area values, but results hold for raw area values as well), indicating that there is a significant amount of area experiencing light turbulence (Fig. 16). This result is consistent with S4, where S4 predicted large areas of light turbulence at 8,10 , and $12 \mathrm{~km}$ in altitude. Interestingly, all of the model setups predict the most light turbulence at $10 \mathrm{~km}$ in altitude with the greatest areal coverage by $\mathrm{S} 3$. The highest EDR values were predicted at $12 \mathrm{~km}$ in altitude for $\mathrm{S} 2-\mathrm{S} 3$, and $8 \mathrm{~km}$ in altitude for $\mathrm{S} 4$. The maximum EDR value was predicted by $\mathrm{S} 4$, suggesting that higher resolution in the vertical and horizontal is needed in order to simulate turbulence intensities similar to observations. On 12 July, all three simulations predicted moderate turbulence at $8 \mathrm{~km}$ or higher, comparable to PIREPs. However, S2 and S4 predicted moderate turbulence at all three height levels, while $\mathrm{S} 3$ predicted moderate turbulence only at 8 and $12 \mathrm{~km}$.

On 13 July, when convection is isolated and weaker in strength, neither S2 nor S3 predict moderate turbulence (Fig. 17). On this particular day, the highest vertical and horizontal resolution is necessary to predict turbulence magnitudes similar to observations.

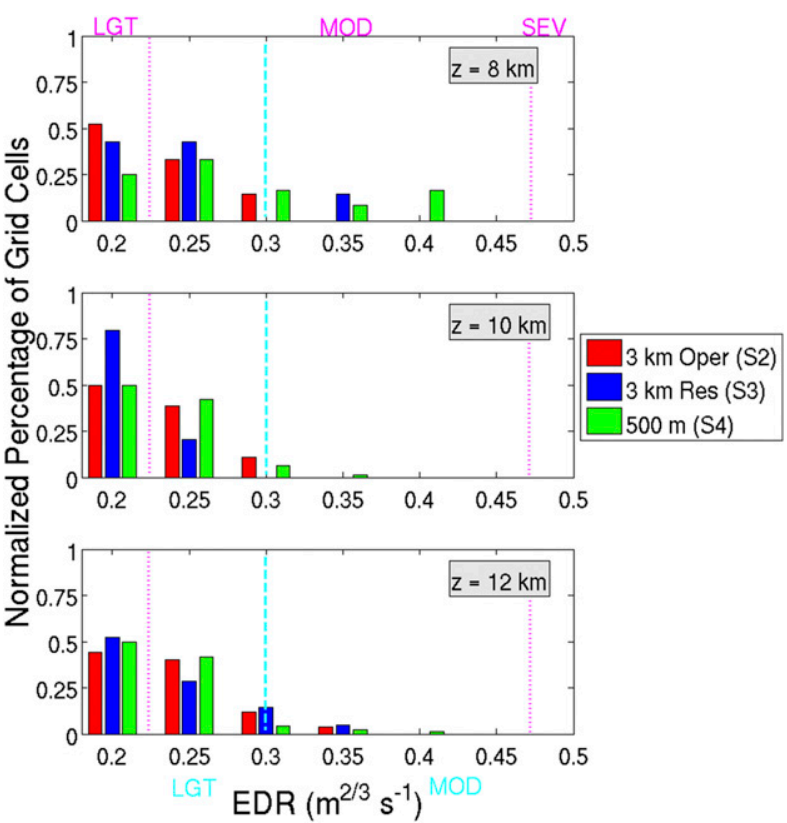

FIG. 16. Out-of-cloud EDR distribution values $\geq 0.2 \mathrm{~m}^{2 / 3} \mathrm{~s}^{-1}$ within $50 \mathrm{mi}$ of convective cores with echo-top heights $\geq 8 \mathrm{~km}$ for S2-S4 on 12 Jul 2015. Dashed (cyan) and dotted (purple) vertical lines represent turbulence intensities based on Lane et al. (2012) and Sharman et al. (2014), respectively.

Last, some moderate values of EDR are evident above $8 \mathrm{~km}$ in all simulations of 15 July (Fig. 18). However, only S4 predicts moderate turbulence at all height levels, where S2 predicts moderate turbulence only at 10 and $12 \mathrm{~km}$ in altitude, and S3 only predicts moderate turbulence at $12 \mathrm{~km}$ in altitude. For convection that is dynamically forced (i.e., synoptic-scale lifting mechanism such as a frontal boundary), as is the case on 15 July, all simulations do produce turbulence with the same magnitude as observations, but the occurrence is highly height dependent. The major differences between turbulence intensity and areal coverage between the various model setups are the higher areal coverages of lower-intensity values for S2 and S3 and the higherintensity EDR values predicted by S4. It is clear that higher horizontal and vertical resolution is necessary to accurately predict turbulence intensity.

\section{d. 10-17 July S2 and S3 comparisons}

A further investigation examines the influence of vertical resolution alone on turbulence intensity using model setups 2 and 3 (64 and 100 vertical levels). These vertical grid spacings represent those used in common operational forecasting frameworks and more research oriented frameworks. Results will be analyzed at 8,10 , and $12 \mathrm{~km}$ in altitude (in cloud and out of cloud) for eight simulation days. Turbulent grid cells within 


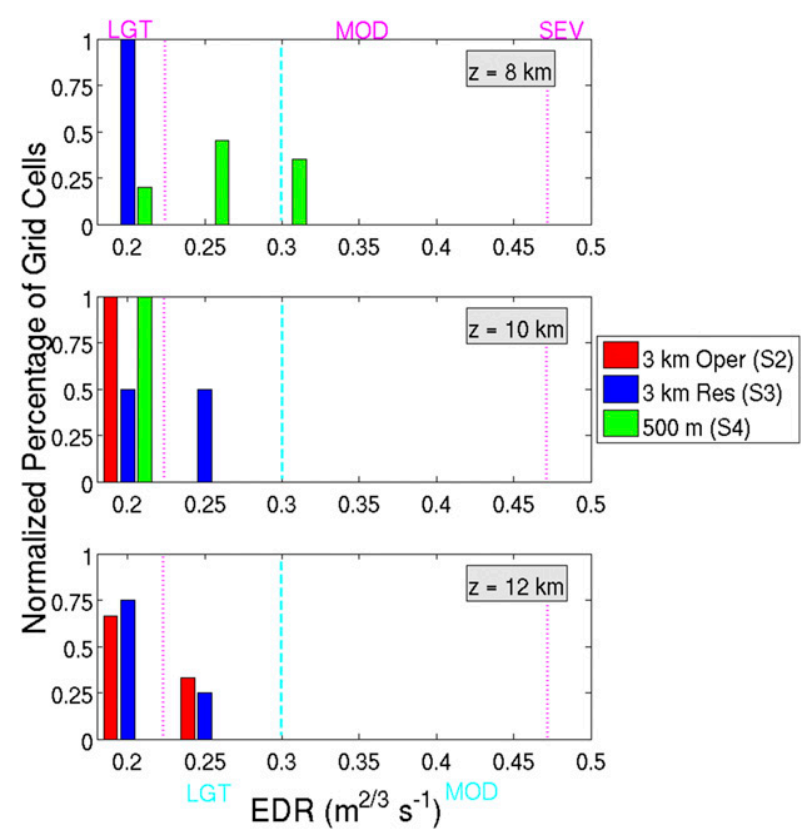

FIG. 17. As in Fig. 16, but for 13 Jul 2015.

convection (in cloud) are now included in the analysis. Seven of the eight simulation days had convection for several hours in the model domain. The purpose of this analysis is to determine if there is a statistical bias in EDR values greater than $0.2 \mathrm{~m}^{2 / 3} \mathrm{~s}^{-1}$ when using two different vertical resolutions.

The number of grid cells for both S2 and S3 that have ETs $\geq 8 \mathrm{~km}$ are determined for each of the eight simulation days (Table 4). Interestingly, S2 predicts more grid cells with ETs $\geq 8 \mathrm{~km}$ in altitude than $\mathrm{S} 3$ for seven of the eight days. This finding is substantial because if ETs were used as the only turbulence proxy, then increased vertical resolution would not positively benefit the prediction of storm depth and intuitively turbulence. Furthermore, as was shown in Figs. 13-15, the maximum hourly ETs predicted by the two 3-km runs were comparable, but still far less than observations. However, a frequency analysis does show that S2 is predicting greater ETs slightly more often than S3, which intuitively influences the turbulence production and strength (Table 4). It would be hypothesized that the model setup with the highest storm heights would produce more turbulence at higher altitudes. Yet, as was discussed in the previous sections (Figs. 16-18), S2 never had the greatest EDR values at 8,10 , or $12 \mathrm{~km}$.

The normalized distribution of EDR values from 10 to 17 July (0600-0600 UTC) for S2 and S3 at 8, 10, and $12 \mathrm{~km}$ are provided in Fig. 19 [comparisons of raw area distributions show similar results (not shown)]. As was noted in the three individual simulation days, S3 has a

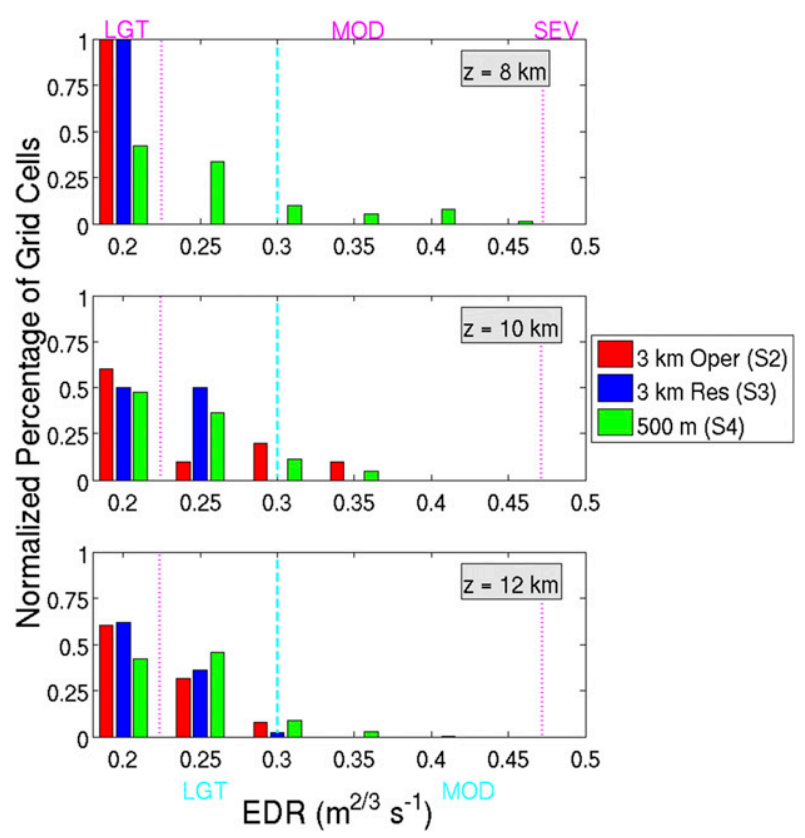

FIG. 18. As in Fig. 16, but for 15 Jul 2015.

greater percentage of grid cells $(59 \%)$ with EDR values between 0.17 and $0.22 \mathrm{~m}^{2 / 3} \mathrm{~s}^{-1}$ than S2 for the 8-day period. S3 also has a larger percentage of grid cells with EDR values between 0.32 and $0.47 \mathrm{~m}^{2 / 3} \mathrm{~s}^{-1}(4 \%)$. However, S2 has a larger percentage of grid cells with EDR values between 0.22 and $0.32 \mathrm{~m}^{2 / 3} \mathrm{~s}^{-1}(35 \%)$. This again demonstrates that higher vertical resolution produces the extremes of the EDR distribution; more widespread light turbulence and more extreme values. However, statistical testing shows that these results are not statistically significant. The coarser vertical resolution (S2) distributes the majority of EDR values within the middle of the spectrum and hardly any in the maximum. If the prediction of turbulence is solely based on exceeding one EDR threshold value such as $0.2 \mathrm{~m}^{2 / 3} \mathrm{~s}^{-1}$, S2 would predict grid cells above this threshold more often than S3, but once again this difference is not statistically significant. However, from this evaluation, it was found that S3 does exceed the EDR threshold of $0.2 \mathrm{~m}^{2 / 3} \mathrm{~s}^{-1}$ more than $\mathrm{S} 2$ when convection was long lasting, extensive in areal coverage, and severe in strength. This finding indicates that convective type does influence turbulence prediction for various model setups.

\section{Discussion and conclusions}

CIT is currently treated as a nowcasting problem because turbulence encounters occur on scales much finer than model resolutions used for forecasting applications. 
TABLE 4. Number of grid cells with echo-top heights $\geq 8 \mathrm{~km}$.

\begin{tabular}{lrr}
\hline \hline Simulation day & S2 & S3 \\
\hline 10 Jul 2015 & 392 & 260 \\
11 Jul 2015 & 1199 & 785 \\
12 Jul 2015 & 1343 & 1139 \\
13 Jul 2015 & 399 & 367 \\
14 Jul 2015 & 380 & 383 \\
15 Jul 2015 & 1353 & 970 \\
16 Jul 2015 & 1554 & 1215 \\
17 Jul 2015 & 764 & 657 \\
\hline
\end{tabular}

Forecasts that predict the intensity of turbulence are generated in 15-min intervals by utilizing several convective and turbulence indices (Pearson and Sharman 2017); however, in-depth details about precise locations of turbulence on $10-1000-\mathrm{m}$ scales are not available. Furthermore, forecasting operations continue to trend toward higher-resolution configurations in both the vertical and horizontal, but performance of these turbulence indices at these higher resolutions has not been examined. This study evaluated turbulence prediction from commonly implemented model configurations (i.e., NAM, HRRR, and research) for numerous convectively active days in the North Dakota region. This study found that simulations with horizontal grid spacing of $12 \mathrm{~km}$ (S1) cannot be used for CIT prediction because this model setup frequently underpredicts convective depth and intensity, unless convection is driven by large-scale forcing. Among the remaining model setups, the simulated convection was not significantly different. In general, convective type and intensity were forecast well. However, all model setups underpredicted maximum storm depth when compared with observations and S2-S3 more often underpredicted storm depth when compared with S4. These consistent errors in storm depth are likely important for forecasting turbulence.

Overall, turbulence forecasts were mixed. The finest model resolution (horizontal and vertical; S4) predicted the most intense turbulence values over small areas. The 3-km simulations (S2 and S3) with varying vertical resolution altered the distribution of lower EDR values that encompass larger areas. The height of maximum turbulence values and areal coverage were also influenced by model resolution. This suggests that the mechanisms that drive turbulence production and propagation are altered by model resolution. This study has demonstrated how turbulence intensity and areal coverage are very sensitive to model resolution, which means scale-aware thresholds are vitally needed.

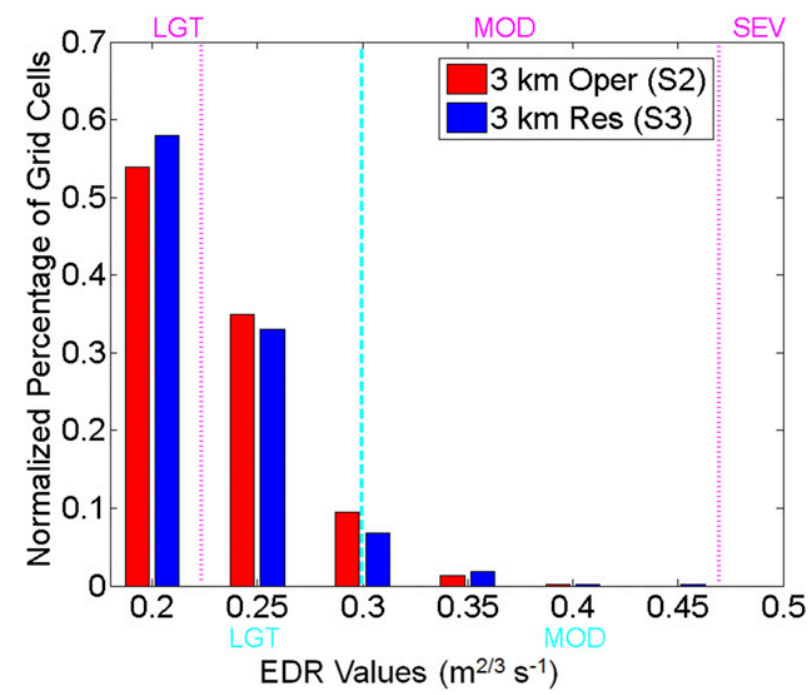

FIG. 19. Distribution of EDR values $\geq 0.2 \mathrm{~m}^{2 / 3} \mathrm{~s}^{-1}$ within $50 \mathrm{mi}$ of convective cores with echo-top heights $\geq 8 \mathrm{~km}$ for S2 and S3 across eight simulation days, combining statistics at 8,10 , and $12 \mathrm{~km}$ in altitude. Dashed (cyan) and dotted (purple) vertical lines represent turbulence intensities based on Lane et al. (2012) and Sharman et al. (2014), respectively.

The Ellrod index, a popular operational diagnostic for turbulence thresholds, was investigated, and while it is an adequate tool for large-scale turbulence prediction (e.g., jet stream turbulence, frontal passage turbulence), it cannot be used as a CIT diagnostic at operational and research model resolutions without coarsening the model input to resolutions used in the original formulation (i.e., $10-100 \mathrm{~km}$ ). Application of TI2 to the latest operational model resolutions (i.e., $3 \mathrm{~km}$ ) will produce unrealistic results. The Ellrod index is very sensitive to model resolution and overpredicts the intensity and areal coverage of turbulence. The Ellrod index used in conjunction with additional products may be effective, but should not be used as an individual diagnostic on resolution scales less than $10 \mathrm{~km}$.

Results from this study show that moderate CIT can surpass the current FAA avoidance guideline of $20 \mathrm{mi}$ $(32.2 \mathrm{~km})$ and can be present out to $50 \mathrm{mi}(80.5 \mathrm{~km})$ from active convection. These results are in agreement with recent studies by Lane et al. (2012), Lane and Sharman (2014), and Zovko-Rajak and Lane (2014). This finding emphasizes how additional research of CIT identification for various types of convection is needed. It also brings into question how efficient and useful strict lateral avoidance thresholds are for avoiding CIT when CIT is variable from storm to storm and spatially limited. For example, on 12 July 2015, above $8 \mathrm{~km}$ in altitude, moderate-to-severe turbulence within 20 and $50 \mathrm{mi}$ of convection covered less than $1 \%$ of those areas. 
Is there a better approach to CIT avoidance when moderate-severe turbulence is extremely spatially limited? Although the areal coverage of the most intense EDR values was spatially limited, the greatest EDR values were found at $8 \mathrm{~km}$ for the highest-resolution simulations and $12 \mathrm{~km}$ for the coarser simulations, which are common altitudes used by commercial aviation. To improve turbulence forecasting tools and redesign avoidance procedures, more observations and research are needed.

Acknowledgments. We thank the three anonymous reviewers for providing suggestions for improvement of the manuscript. We also thank Wiebke Deierling and Robert Sharman from NCAR for their constructive feedback on this work. The authors were supported by the Northrop Grumman Corporation and the North Dakota Experimental Program to Stimulate Competitive Research (EPSCoR) through the National Science Foundation Grant IIA-1355466. This work used the XSEDE Comet at the SDSC through allocation ATM110005; XSEDE is supported by National Science Foundation Grant ACI-1548562.

\section{REFERENCES}

Ahmad, N. N., and F. H. Proctor, 2012: Estimation of eddy dissipation rates from mesoscale model simulations. NASA Tech. Report AIAA Paper-2012-0429, 24 pp, https://ntrs.nasa.gov/ search.jsp? $\mathrm{R}=20120000925$.

Barber, K. A., 2015: Simulations of convectively-induced turbulence based on radar-based climatology of tropical storm types. M.S. thesis, Dept. of Atmospheric Sciences, University of North Dakota, $169 \mathrm{pp}$.

Behne, D., 2008: NAM-WRF verification of subtropical jet and turbulence. Electron. J. Oper. Meteor., 2008-EJ-3, http:// nwafiles.nwas.org/ej/pdf/2008-EJ3.pdf.

Bernardet, L. R., L. D. Grasso, J. E. Nachamkin, C. A. Finley, and W. R. Cotton, 2000: Simulating convective events using a highresolution mesoscale model. J. Geophys. Res., 105, 14963 14 982, https://doi.org/10.1029/2000JD900100.

Brown, R., 1973: New indices to locate clear air turbulence. Meteor Mag., 102, 347-361.

Bryan, G. H., J. C. Wyngaard, and J. M. Fritsch, 2003: Resolution requirements for the simulation of deep moist convection. Mon. Wea. Rev., 131, 2394-2416, https://doi.org/10.1175/ 1520-0493(2003)131<2394:RRFTSO > 2.0.CO;2.

Cornman, L. B., C. S. Morse, and G. Cunning, 1995: Real-time estimation of atmospheric turbulence severity from in-situ aircraft measurements. J. Aircr., 32, 171-177, https://doi.org/ $10.2514 / 3.46697$.

Creighton, G., and Coauthors, 2014: AFWA diagnostics in WRF. AFWA Rep., 17 pp.

Doyle, J. D., and Coauthors, 2011: An intercomparison of T-REX mountain-wave simulations and implications for mesoscale predictability. Mon. Wea. Rev., 139, 2811-2831, https://doi.org/ 10.1175/MWR-D-10-05042.1.
Dutton, M. J. O., 1980: Probability forecasts of clear-air turbulence based on numerical output. Meteor. Mag., 109, 293-310.

Ellrod, G. P., and D. I. Knapp, 1992: An objective clear-air turbulence forecasting technique: Verification and operational use. Wea. Forecasting, 7, 150-165, https://doi.org/10.1175/ 1520-0434(1992)007<0150:AOCATF>2.0.CO;2.

- , and J. A. Knox, 2010: Improvements to an operational clearair turbulence diagnostic index by addition of a divergence trend term. Wea. Forecasting, 25, 789-798, https://doi.org/ 10.1175/2009WAF2222290.1.

Emanuel, M., J. Sherry, S. Catapano, L. Cornman, and P. A. Robinson, 2013: In situ performance standard for eddy dissipation rate. 16th Conf. on Aviation, Range, and Aerospace Meteorology, Austin, TX, Amer. Meteor. Soc., 11.3, https:// ams.confex.com/ams/93Annual/webprogram/Manuscript/ Paper219007/In \%20Situ \%20Performance\%20Standard\% 20for \%20Eddy\%20Dissipation \%20Rate \%20-\%202013-0208.pdf.

Federal Aviation Administration, 2017: Safety of flight. Aeronautical Information Manual: Official Guide to Basic Flight Information and ATC Procedures, U.S. Dept. of Transportation, 435-539, https://www.faa.gov/air_traffic/publications/ media/AIM Basic dtd 10-12-17.pdf.

Golding, W. L., 2000: Turbulence and its impact on commercial aviation. J. Aviat. Aerosp. Ed. Res., 11, 19-29.

Janjić, Z., 1994: The step-mountain eta coordinate model: Further developments of the convection, viscous sublayer, and turbulence closure schemes. Mon. Wea. Rev., 122, 927-945, https:// doi.org/10.1175/1520-0493(1994)122<0927:TSMECM >2.0.CO;2.

Kim, J.-H., and H.-Y. Chun, 2012: A numerical simulation of convectively induced turbulence above deep convection. J. Appl. Meteor. Climatol., 51, 1180-1200, https://doi.org/ 10.1175/JAMC-D-11-0140.1.

,,-- R. D. Sharman, and S. B. Trier, 2014: The role of vertical shear on aviation turbulence within cirrus bands of a simulated western Pacific cyclone. Mon. Wea. Rev., 142, 2794 2813, https://doi.org/10.1175/MWR-D-14-00008.1.

Lane, T. P., and J. C. Knievel, 2005: Some effects of model resolution on simulated gravity waves generated by deep, mesoscale convection. J. Atmos. Sci., 62, 3408-3419, https://doi.org/ 10.1175/JAS3513.1.

- and R. D. Sharman, 2014: Intensity of thunderstormgenerated turbulence revealed by large-eddy simulation. $G e$ ophys. Res. Lett., 41, 2221-2227, https://doi.org/10.1002/ 2014GL059299.

_, - _, T. L. Clark, and H.-M. Hsu, 2003: An investigation of turbulence generation mechanisms above deep convection. J. Atmos. Sci., 60, 1297-1321, https://doi.org/ 10.1175/1520-0469(2003)60<1297:AIOTGM>2.0.CO;2.

, J. D. Doyle, R. D. Sharman, M. A. Shapiro, and C. D. Watson, 2009: Statistics and dynamics of aircraft encounters of turbulence over Greenland. Mon. Wea. Rev., 137, 2687-2702, https://doi.org/10.1175/2009MWR2878.1.

, R. D. Sharman, S. B. Trier, R. G. Fovell, and J. K. Williams, 2012: Recent advances in the understanding of near-cloud turbulence. Bull. Amer. Meteor. Soc., 93, 499-515, https:// doi.org/10.1175/BAMS-D-11-00062.1.

Lester, P. F., 1994: Turbulence: A New Perspective for Pilots. Jeppesen Sanderson, $212 \mathrm{pp}$.

McNulty, R. P., 1995: Severe and convective weather: A central region forecasting challenge. Wea. Forecasting, 10, 187-202, https:// doi.org/10.1175/1520-0434(1995)010<0187:SACWAC >2.0.CO;2. 
Muñoz-Esparza, D., J. A. Sauer, R. R. Linn, and B. Kosović, 2016: Limitations of one-dimensional mesoscale PBL parameterizations in reproducing mountain-wave flows. J. Atmos. Sci., 73, 2603-2614, https://doi.org/10.1175/JAS-D-15-0304.1.

Pantley, K. C., 1989: Turbulence near thunderstorm tops. M.S. thesis, Dept. of Meteorology, San Jose State University, 132 pp.

Pearson, J. M., and R. D. Sharman, 2017: Prediction of energy dissipation rates for aviation turbulence. Part II: Nowcasting convective and nonconvective turbulence. J. Appl. Meteor. Climatol., 56, 339-351, https://doi.org/10.1175/JAMC-D-16-0312.1.

Poellot, M. R., and C. A. Grainger, 1991: A comparison of several airborne measures of turbulence. Preprints, Fourth Int. Conf. of the Aviation Weather Systems, Paris, France, Amer. Meteor. Soc., 90-93.

Sauer, J. A., D. Muñoz-Esparza, J. M. Canfield, K. R. Costigan, R. R. Linn, and Y.-J. Kim, 2016: A large-eddy simulation study of atmospheric boundary layer influence on stratified flows over terrain. J. Atmos. Sci., 73, 2615-2632, https://doi.org/ 10.1175/JAS-D-15-0282.1.

Schumann, U., 1991: Subgrid length-scales for large-eddy simulation of stratified turbulence. Theor. Comput. Fluid Dyn., 2, 279-290, https://doi.org/10.1007/BF00271468.

Sharman, R. D., and J. M. Pearson, 2017: Prediction of energy dissipation rates for aviation turbulence. Part I: Forecasting nonconvective turbulence. J. Appl. Meteor. Climatol., 56, 317337, https://doi.org/10.1175/JAMC-D-16-0205.1.

, C. Tebaldi, G. Wiener, and J. Wolff, 2006: An integrated approach to mid- and upper-level turbulence forecasting. Wea. Forecasting., 21, 268-287, https://oi.org/10.1175/ WAF924.1.

— J. D. Doyle, and M. A. Shapiro, 2012: An investigation of a commercial aircraft encounter with severe clear-air turbulence over western Greenland. J. Appl. Meteor. Climatol., 51, 42-53, https://doi.org/10.1175/JAMC-D-11-044.1.

, L. B. Cornman, G. Meymaris, J. Pearson, and T. Farrar, 2014: Description and derived climatologies of automated in situ eddy-dissipation-rate reports of atmospheric turbulence. J. Appl. Meteor. Climatol., 53, 1416-1432, https://doi.org/ 10.1175/JAMC-D-13-0329.1.

Skamarock, W. C., and J. B. Klemp, 2008: A time-split nonhydrostatic atmospheric model for weather research and forecasting applications. J. Comput. Phys., 227, 3465-3485, https://doi.org/10.1016/j.jcp.2007.01.037.

Stephan, C., and M. J. Alexander, 2014: Summer season squall-line simulations: Sensitivity of gravity waves to physics parameterization and implications for their parameterization in global climate models. J. Atmos. Sci., 71, 3376-3391, https://doi.org/ 10.1175/JAS-D-13-0380.1.

Towns, J., and Coauthors, 2014: XSEDE: Accelerating scientific discovery. Comput. Sci. Eng., 16, 62-74, http:// doi.ieeecomputersociety.org/10.1109/MCSE.2014.80.

Trier, S. B., and R. D. Sharman, 2016: Mechanisms influencing cirrus banding and aviation turbulence near a convectively enhanced upper-level jet stream. Mon. Wea. Rev., 144, 30033027, https://doi.org/10.1175/MWR-D-16-0094.1.

$\longrightarrow,-$, R. G. Fovell, and R. G. Frehlich, 2010: Numerical simulation of radial cloud bands within the upper-level outflow of an observed mesoscale convective system. J. Atmos. Sci., 67, 2990-2999, https://doi.org/10.1175/2010JAS3531.1.

U.S. Department of the Air Force, 1982: Weather for Aircrews. Air Force Manual 51-12, Vol. 1, Dept. of the Air Force, 187 pp.

Wakimoto, R. M., and H. V. Murphey, 2009: Analysis of a dryline during IHOP: Implications for convection initiation. Mon. Wea. Rev., 137, 912-936, https://doi.org/10.1175/2008MWR2584.1.

Weisman, M. L., C. Davis, W. Wang, K. W. Manning, and J. B. Klemp, 2008: Experiences with 0-36-h explicit convective forecasts with the WRF-ARW model. Wea. Forecasting, $\mathbf{2 3}$, 407-437, https://doi.org/10.1175/2007WAF2007005.1.

Williams, J. K., G. Meymaris, J. Craig, G. Blackburn, W. Deierling, and F. McDonough, 2011: Measuring in-cloud turbulence: The NEXRAD turbulence detection algorithm. 15th Conf. on Aviation, Range and Aerospace Meteorology, Los Angeles, CA, Amer. Meteor. Soc., 2.1, https://ams.confex.com/ ams/14Meso15ARAM/webprogram/Handout/Paper191252/ 021_williams.pdf.

Wolff, J. K., and R. D. Sharman, 2008: Climatology of upperlevel turbulence over the contiguous United States. J. Appl. Meteor. Climatol., 47, 2198-2214, https://doi.org/10.1175/ 2008JAMC1799.1.

Zovko-Rajak, D., and T. P. Lane, 2014: The generation of nearcloud turbulence in idealized simulations. J. Atmos. Sci., $\mathbf{7 1}$, 2430-2451, https://doi.org/10.1175/JAS-D-13-0346.1. 